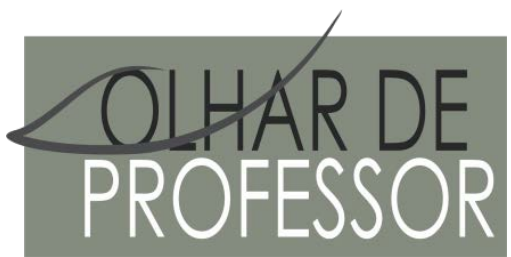

DOI: 10.5212/OLHARPROFR.v.21i1.0005

\title{
O CONTEXTO FORMATIVO NO CENTRO DE EDUCAÇ̃̃o INFANTIL: A COORDENAÇÃo PEDAGÓGICA E AS PROFESSORAS DE BEBÊS E CRIANÇAS MUITO PEQUENAS
}
THE FORMATIVE CONTEXT IN A DAY CARE/CHILDHOOD CENTER: THE PEDAGOGICAL COORDINATION AND THE TEACHERS OF BABIES AND LITTLE CHILDREN

\section{EL CONTEXTO FORMATIVO EN LAS GUARDERIAS: LA COORDINACIÓN PEDAGÓGICA Y LAS PROFESORAS DE BEBÉS Y NIÑOS MUY PEQUEÑNOS}

\author{
RAQUEL MARIA BORTONE FERMI ${ }^{*}$ \\ MARLI ELIZA DALMAZO AFONSO DE ANDRÉ ${ }^{* \star}$
}

\begin{abstract}
Resumo: O objetivo deste texto é analisar o trabalho de uma coordenadora pedagógica, reconhecida por sua prática exitosa, em um Centro de Educação Infantil (CEI)/creche da Rede Municipal de São Paulo com especial atenção em sua atuação no contexto formativo junto às professoras da pequena infância. As análises são decorrentes do conjunto de dados produzidos durante a pesquisa realizada para o trabalho final do Mestrado. A coleta de dados foi realizada por meio de entrevistas individuais, discussões coletivas, observação e análise de documentos. Os seguintes referenciais teóricos, dentre outros foram consultados: Almeida e Placco (2009), André e Vieira (2010), Almeida (2010), Imbernón (2010). Os resultados obtidos reafirmam a atuação distintiva dessa profissional na formação continuada das professoras para contemplar as especificidades do atendimento a crianças dessa faixa etária.
\end{abstract}

Palavras-chave: Coordenador pedagógico. Formação continuada. Pequena infância.

\begin{abstract}
The aim of this study is to address the successful performance of a pedagogical coordinator in a day care/childhood center for early of the Municipal in the city of São Paulo with special attention to the training context with the childhood teachers. The analyses are derived from the set of data produced during the research conducted for the Professional Master's degree. Data collection was performed through individual interviews, collective discussions, observation and document analysis. The theoretical frameworks, among others, were consulted: Almeida e Placco (2009), André and Vieira (2010), Almeida (2010), Imbernòn (2010). The results obtained reaffirm the relevance of this professional in the continued teacher education to better attend children in early childhood.
\end{abstract}

Key words: Pedagogical Coordinator. Continued teacher education. Early childhood.

\footnotetext{
* Graduada em História e Pedagogia. Mestre em Educação pelo Programa Formação de Formadores da PUC-SP. Supervisora escolar aposentada da RME de São Paulo. Correio eletrônico: rchector@gmail.com

** Ph.D em Psicologia da Educação pela Universidade de Illinois (USA) em 1978. Professora dos Programas de Educação: Psicologia da Educação e Formação de Formadores da PUC SP. Correio eletrônico: marli.andre@gmail.com
} 
Resumen: El objetivo de este estudio es abordar el exitoso desempeño de una coordinadora pedagógica en una guardería de la ciudad de São Paulo y las relaciones establecidas en este contexto formativo con los profesores de la Infancia. Los análisis se derivan del conjunto de datos producidos durante la investigación llevada a cabo para el Máster Profesional. La recopilación de datos se realizó a través de entrevistas individuales, discusiones colectivas, observación y análisis de documentos. Se consultó a los siguientes marcos teóricos, entre otros: Almeida y Placco (2009), André y Vieira (2010), Almeida (2010), Imbernòn (2010). Los resultados obtenidos reafirman la relevancia de esta profesional para la formación continuada de las maestras para actuar con los niños de la pequeña infancia.

Palabras clave: Coordinador pedagógico. Formación continua. Pequeña infancia

\section{INTRODUÇÃO}

As análises presentes neste trabalho são decorrentes da pesquisa "A atuação do Coordenador Pedagógico no CEI: Construindo novos caminhos entre a prática e a reflexão”, realizada para o trabalho final do mestrado. O objetivo da pesquisa foi analisar a atuação da coordenadora pedagógica, em especial nos espaços de formação continuada. Esse trabalho possui características de um estudo de caso, pois seu objeto de estudo foi a atuação de uma profissional reconhecida em seu meio por suas características distintivas. De acordo com Lüdke e André: “O caso pode ser similar a outros, mas é ao mesmo tempo distinto, pois tem um interesse próprio, singular.” (2014, p. 20).

Partindo-se do objetivo central, a pesquisa buscou identificar: a) as ações formativas planejadas e desenvolvidas pela coordenadora pedagógica no cotidiano do CEI: b) captar as opiniões dos professores e da diretora da creche sobre as ações da coordenadora; e c) conhecer a trajetória profissional da coordenadora.

Frente a esses objetivos, foram coletados e registrados dados que poderiam ampliar a compreensão dos aspectos singulares dessa profissional, assim como do contexto em que atuava. Para a coleta de dados foram utilizados os seguintes procedimentos metodológicos: observação, análise documental, entrevista e grupos de discussão. Os dados coletados por meio desses procedimentos foram analisados e agrupados em quatro categorias: a constituição profissional da coordenadora pedagógica, suas estratégias formativas, o conteúdo das formações e a avaliação da equipe.

O local escolhido para a pesquisa tinha relativo destaque junto à secretaria de educação e era conhecido por desenvolver um currículo que primava por experiências diversificadas com o brincar, a liberdade de imaginar e criar e de contar com a participação das famílias das crianças. Tratava-se de uma creche da rede direta ${ }^{1}$, situada na zona sul de São Paulo. Foi criada em 1990, num bairro de classe média de São Paulo. Em 2016, ano em que houve a coleta de dados para a pesquisa, eram atendidas nessa unidade 109 crianças de 0 a 3 anos. A demanda atendida era constituída em grande parte por filhos de trabalhadores da região.

Dessa forma, neste artigo, busca-se acrescentar subsídios à discussão acerca da relação entre a coordenadora pedagógica e a formação continuada dos professores de bebês e crianças muito pequenas $^{2}$. Partindo do pressuposto que a formação continuada é uma dimensão fundamental para o desenvolvimento profissional dos professores, consideramos essa discussão importante, uma vez que a formação inicial nem sempre garante aos recém-licenciados, os saberes necessários para lidar com as especificidades da Educação Infantil. Em entrevista, Barreto (2011 p. 3) declara:

\footnotetext{
${ }^{1}$ Esse CEI é uma unidade administrada diretamente pela SME, os funcionários são concursados e pertencem ao quadro do funcionalismo municipal.

${ }^{2}$ Segundo a Base Curricular Comum Nacional (BCCN), homologada em 14 de dezembro de 2018 pelo Ministério da Educação. Na educação infantil o documento se refere à creche e pré-escola. Na creche são considerados dois agrupamentos: bebês (zero a 1 ano e 6 meses) e crianças muito pequenas ( 1 ano e 7 meses a 3 anos e 11 meses).
} 
“Os cursos de Pedagogia, responsáveis pela formação dos professores dos anos iniciais do ensino fundamental e da educação infantil, costumam ser muito genéricos e falta-lhes um foco claro no preparo para o magistério.”

O enunciado de Barreto explicita que o professor em geral, chega à creche para trabalhar com os bebês ou as crianças bem pequenas, mas não recebeu uma formação inicial específica e pouco conhece sobre as diversas dimensões dessa atuação.

Contudo, antes de nos aprofundarmos nessas questões, é imprescindível resgatar o que caracteriza esses espaços, considerando suas especificidades históricas. Para tanto, a história das creches e principalmente das creches paulistanas, será abordada brevemente neste trabalho.

\section{UM POUCO DA HISTÓRIA}

No início do século XX, a história do atendimento em creches no Brasil foi assinalada pelo desenvolvimento da industrialização e urbanização do país. Predominou, nessa história, uma concepção assistencialista de atendimento à criança que primava pelo cuidar. Nos anos 1970, a luta de mães trabalhadoras obrigou o Estado a ampliar o atendimento em creches, vinculando esse atendimento a um direito das famílias trabalhadoras.

Mais tarde, com o processo de redemocratização do país, foi promulgada a Constituição Federal em 1988 que estabeleceu o dever do Estado na garantia dos direitos subjetivos dos cidadãos, as competências da união, estados e municípios em relação à educação e a garantia de atendimento às crianças de zero a seis anos ${ }^{3}$ de idade em creches e pré-escolas.

Na sequência, no ano de 1990 foi homologado o Estatuto da Criança e do Adolescente, e a Lei de Diretrizes e Bases da Educação Nacional (LDBEN), de 1996. Com a LDBEN, a Educação Infantil passou a integrar a Educação Básica, com a finalidade de garantir o desenvolvimento integral da criança de até seis anos ${ }^{4}$, em seus aspectos físicos, psicológicos, intelectuais e sociais, complementando a ação da família e da comunidade.

A LDBEN determinou ainda que, a Educação Infantil fosse oferecida em creches, ou entidades equivalentes, para crianças de até três anos de idade e pré-escolas para as crianças de quatro a seis anos de idade. Foi estabelecido o prazo de 3 anos, a partir da publicação da lei, para que as creches fossem integradas aos sistemas de ensino. Nesse momento, o atendimento em creches ganhou novos contornos e para definir algumas diretrizes foi publicada pelo Ministério da Educação a Resolução nº 1 , em 07 de abril de 1999, que fixava as Diretrizes Nacionais para a Educação Infantil.

Na cidade de São Paulo, a transição destes equipamentos da assistência social para a educação aconteceu entre os anos 2001 e 2002. Nessa cidade, assim como em outras, ir além das práticas que primam pelos cuidados específicos com crianças de 0 a 3 anos incompletos, pode ser considerada uma jornada não consumada no cotidiano de muitas creches. Dessa forma, propostas pedagógicas que possibilitem às crianças experiências de socialização, brincadeiras, convivência e atendimento às suas necessidades são essenciais para a garantia do direito a uma educação integral.

Atualmente, nos CEIs da cidade de São Paulo atuam professores que fizeram a transição em 2002, anteriormente denominados de Auxiliares de Desenvolvimento Infantil (ADIs). Grande parte desses professores cursou a faculdade de Pedagogia ou participaram do curso ADI Magistério, um programa de formação promovido pela Secretaria Municipal de Educação e coordenado pela Fundação Carlos Alberto Vanzolini. Este curso foi realizado entre 2002 e 2004. O referido programa tinha o propósito de dar formação de nível médio e promover especialização às auxiliares de desenvolvimento

\footnotetext{
${ }^{3}$ A Emenda Constitucional n ${ }^{\circ} 53$ de 19 de dezembro de 2006 altera a idade para até 5 anos.

${ }^{4}$ Com a publicação da Lei 12.796 em 04 de abril de 2013, a Educação Infantil será oferecida par crianças até 5 anos.
} 
infantil que a partir de então, acessaram o cargo de Professores de Desenvolvimento Infantil (PDI). Após 2007, esses professores passaram a ser designados como Professores de Educação Infantil (PEI). Muitos professores ingressaram na carreira, nos últimos anos, por meio de concurso público, com formação em Pedagogia.

Entretanto, o ingresso de pedagogos nos CEIs não garantiu por si só, um trabalho pedagógico de qualidade. Algumas pesquisas, como as realizadas por Campos (1999, 2003); Campos, Fullgraf e Wiggers (2006) e Gatti (2010) revelaram que, para além do fato da formação inicial não preparar o professor para as especificidades da educação infantil, os professores da creche encontram dificuldades para superar algumas ações pedagógicas cristalizadas que não atendem aos conceitos de qualidade expressos nos documentos oficiais. É comum encontrarmos traços de um atendimento marcado pelo assistencialismo, pouco voltado para o desenvolvimento pleno das crianças. Estudar e discutir a respeito da educação coletiva de crianças pequenas, ainda é necessário. Bruno, Abreu e Monção (2012, p. 80) nos propõem que:

No que se refere à legislação, atualmente contamos com um corpo de leis que sustentam e regulamentam a educação infantil - Constituição Federal, Leis de Diretrizes e Bases da Educação, Diretrizes Nacionais para a Educação Infantil -, entretanto ainda há uma lacuna entre as conquistas legais, as políticas públicas de educação infantil e as práticas que ocorrem no interior das unidades de educação infantil.

Em relação à realidade apresentada na citação acima, percebe-se que estamos diante de um impasse. Porém, com base na literatura correlata ao tema, compreendemos que na realidade, os professores da creche agregam às suas práticas, fazeres e saberes específicos, oriundos das experiências vivenciadas no interior da instituição por meio das relações estabelecidas com as crianças, com o coletivo de professores e com a equipe gestora, como afirma Dagnoni (2011, p. 6):

Destaca-se também um saber específico do cotidiano da creche, que se constitui de forma singular durante as práticas com os bebês e agrega as experiências profissionais e pessoais das professoras numa cultura própria da creche.

Evidencia-se, no excerto acima, que as trajetórias da vida pessoal e profissional dos professores contribuem para constituição de sua profissionalidade, pois seu fazer pedagógico é constituído por saberes que adquirem ao longo da vida, assim como, por meio da convivência com seus pares. Portanto, organizar ações de formação continuada, nos contextos de trabalho é fundamental para o desenvolvimento profissional desses docentes.

A necessidade de pensar em práticas pedagógicas na educação da pequena infância é referendada nos documentos oficiais publicados pelo Ministério da Educação, na documentação da Secretaria Municipal de Educação de São Paulo e na literatura referente à Educação Infantil. Podemos citar, por exemplo, a revisão das Diretrizes Curriculares Nacionais para a Educação Infantil. (BRASIL, 2009). Esse documento explicita a necessidade de garantir o bem-estar das crianças matriculadas nas creches e indica a necessidade de revisão das concepções sobre educação de crianças em espaços coletivos, o fortalecimento de práticas pedagógicas que possibilitem aprendizagens e desenvolvimento integral das crianças. Barbosa (2010, p. 5) explicita a dimensão das mudanças necessárias:

Educar bebês não significa apenas a constituição e a aplicação de um projeto pedagógico objetivo, mas colocar-se, física e emocionalmente, à disposição das crianças, o que exige dos adultos comprometimento e responsabilidade.

As palavras de Barbosa nos levam a considerar que as relações entre as crianças e seus educadores são estabelecidas por meio das rotinas instituídas e essas orientam as atividades desenvolvidas durante a permanência das crianças nesse espaço educativo. A forma como o professor constitui essa rotina, diz muito do que sabe a respeito de bebês e crianças pequenas. Revela ainda, suas 
concepções de educação infantil e criança. Nesse ponto, chegamos a uma questão fundamental para dar prosseguimento às análises: Qual é o papel da formação continuada para esses professores? Qual é o papel do coordenador pedagógico em relação à formação continuada que ocorre no interior dessas unidades educativas?

Como já afirmado, a formação continuada é um processo coletivo, que acontece durante toda a trajetória profissional dos professores e que se torna mais efetiva se oferece oportunidade para reflexão e troca de experiências entre os pares, possibilitando ainda o desenvolvimento da profissionalidade e a constituição da identidade profissional de seus participantes, como defendido por Imbernón (2010, p. 79) no trecho reproduzido abaixo:

É imprescindível uma alternativa de formação que aceite a reivindicação desse eu, da subjetividade dos professores, da identidade docente como um dinamismo da forma de ver e de transformar a realidade social e educacional, e seus valores, e da capacidade de produção de conhecimento educativo e de troca de experiências.

Concordando com as proposições do autor, cabe destacar o papel fundamental do coordenador pedagógico na articulação do processo formativo nas escolas e nos CEIs. E para esclarecer melhor esse papel, buscamos fontes de referência que tratam dessa questão, como os escritos de Almeida e Placco (2009), André e Vieira (2010) e Almeida (2010), que acentuam o papel articulador da coordenação pedagógica na condução do processo de formação continuada e no desenvolvimento do projeto pedagógico da escola.

Ao optar pelo estudo da ação de uma coordenadora pedagógica, explicita-se a necessidade de responder às questões colocadas acima e compreender de que forma a atuação dessas profissionais pode ser potencializada, para promover formação significativa para os professores.

Uma vez definido o foco da pesquisa, cumpre tratar com mais detalhes da transição das creches, da Secretaria de Assistência Social (SAS) para os quadros da Secretaria Municipal de Educação (SME). Em seguida, serão apontados aspectos relativos à formação continuada dos professores da pequeníssima infância e por fim, serão apresentados os resultados da pesquisa.

\section{COMO UM SOPRO, LÁ SE FORAM 16 ANOS}

A transição das creches da Secretaria de Assistência Social (SAS) para a Secretaria Municipal de Educação (SME) de São Paulo foi um processo decorrente da promulgação da Lei de Diretrizes e Bases da Educação Nacional (LDBEN) de 1996. A partir dessa determinação legal, as creches deveriam fazer parte dos sistemas de ensino. Segundo Franco (2009), na cidade de São Paulo, algumas tentativas governamentais foram feitas para atender a LDBEN entre os anos de 1999 a 2000, mas o processo foi efetivamente realizado entre os anos de 2001 a 2002.

Esse processo não abrangeu apenas os aspectos administrativos de gerenciamento desses equipamentos sociais, mas representou uma mudança no paradigma do atendimento dessas instituições desde seu surgimento. A educação infantil, especialmente o atendimento da faixa etária de 0 a 3 anos, deixou de ter um caráter assistencial e passou a ser entendido como um direito da criança, com o objetivo de garantir educação e desenvolvimento aos pequenos. Essa integração ao sistema educativo proporcionou novas perspectivas e concepções em relação ao trabalho realizado nas creches.

Segundo Franco (2009), foi um processo mediado por diversas ações conjuntas entre as duas secretarias. Muitas adequações foram necessárias para que o atendimento às crianças fosse garantido sem prejuízos. O quadro de funcionários das creches, sob a administração de SAS, contava, à época, dentre outros cargos, com um Diretor de Equipamento Social e Pedagogos. Mediante as regras estabelecidas nesse processo de transição, esses profissionais puderem transformar seus cargos para fazer parte dos quadros de SME. Vale ressaltar que, segundo Franco (2009, p. 60), no período da transição para a SME, apenas $18 \%$ das creches contavam com um pedagogo. 
Em maio de 2003, com a publicação da Lei 13.574, foram criados 400 cargos de coordenadores pedagógicos nos CEIs da rede direta. ${ }^{5}$ Esses cargos foram disponibilizados no final desse ano para 0 concurso de remoção dos coordenadores pedagógicos da rede. Assim, em janeiro de 2004 algumas dessas unidades receberam os coordenadores pedagógicos, alguns deles egressos de escolas de Ensino Fundamental.

Esses marcos da história dos CEIs dão um novo contorno para o trabalho desenvolvido nessas unidades. Retomando Franco (2009), fica claro que esse processo garantiu mudanças significativas em relação às políticas para a Educação Infantil, mas a autora considera que há muito a ser feito para garantir o direito das crianças em relação à qualidade do atendimento.

De acordo com Ana Lúcia Borges, que escreveu um artigo para uma revista institucional da SME, em 2018, há muitos desafios que se impõem aos CEIs ainda hoje:

\begin{abstract}
Penso que para superar estes modelos curriculares na creche, essas rotinas prescritivas, as relações adultocêntricas, entre outros elementos próprios de uma pedagogia escolarizante, há que se investir esforços na formação continuada dos(as) professores(as) dentro do ambiente de trabalho a partir da reflexão sobre a própria prática. (SÃO PAULO, 2018, p. 25).
\end{abstract}

Nesse sentido, apostou-se na atuação do coordenador pedagógico para promover a discussão e reflexão sobre as práticas desenvolvidas nesses espaços. Esse profissional pode ter um importante papel na superação da dicotomia entre cuidar e educar, assim como diante de outros problemas que surgiram com a inclusão das creches na agenda da educação, por exemplo, a tendência de escolarizar as práticas cotidianas.

Para complementar esses apontamentos, ressaltamos que a coordenadora pedagógica, foco principal da pesquisa relatada nesse texto, fez parte do grupo de coordenadores pedagógicos que se removeram para um CEI em 2004. Os desafios enfrentados nesse período e o depoimento das professoras que estavam no CEI nesse momento, nos deram uma dimensão bem definida da importância de sua atuação para o desenvolvimento da ação pedagógica desse período.

\title{
ARTICULANDO SABERES: VIVENCIAS NO CEI
}

A formação continuada deve aprimorar as práticas pedagógicas, pois além de ser um direito do profissional da educação, segundo Imbernón (2011) é um elemento fundamental no desenvolvimento profissional dos docentes. Em termos mais específicos, a formação continuada dos profissionais que atuam com crianças muito pequenas é fundamental, devido às especificidades da faixa etária atendida. As necessidades de cuidado e educação exigem muito dos professores. Ser professor da infância requer conhecimentos específicos e muita reflexão acerca da prática docente.

Consideramos que alguns saberes são relevantes para que os professores dessa faixa etária desenvolvam seu trabalho adequadamente, superando algumas formas já muito cristalizadas nos CEIs. São saberes que devem constituir os conteúdos dos processos formativos. Dentre eles, destacamos a organização dos espaços, garantindo-se o conforto e as condições para a exploração dos objetos e do ambiente pelos bebês e crianças. Os ambientes devem ser acolhedores e lúdicos e que permitam diversas interações:

Portanto, não basta a criança estar em um espaço organizado de modo a desfiar suas competências; pé preciso que ela interaja com esse espaço para vivê-lo intencionalmente. Isso quer dizer que essas vivencias, na realidade, estruturam-se

\footnotetext{
${ }^{5}$ CEIs da rede direta são aqueles que funcionam exclusivamente com funcionários públicos do município. A SME mantém parcerias com Organizações da Sociedade Civil para dar atendimento às crianças de 0 a 3 anos. Essas unidades compõem a rede indireta/parcerias.
} 
em uma rede de relações e expressam-se em papeis que as crianças desempenham em um contexto do qual os moveis, os materiais, os rituais de rotina, a professora e avida das crianças fora da escola interferem nessas vivencias. (ROSSETTIFERREIRA apud HORN, 2004, p. 15).

A autora nos propicia a dimensão exata da importância desse saber relacionado à organização dos espaços. É fundamental para o desenvolvimento da criança que ela crie uma rede de interações, facilitada pela forma como são organizados os móveis, objetos e brinquedos no espaço em que ela se movimenta.

Mas, além da organização dos espaços, é importante que o professor seja instigado a pensar na forma como organiza os tempos, possibilitando que as necessidades físicas, psíquicas e de socialização sejam atendidas. Torna-se fundamental que haja uma reflexão crítica e coletiva a respeito das vivências e experiências que estão sendo proporcionadas às crianças. De acordo com Goldschmied e Jackson (2006, p. 39):

Por meio de previsão e arranjo imaginativos dos materiais para brincar, o adulto possibilita às crianças que escolham e desenvolvam o seu brincar por si mesmas ou com outras.

Outro elemento que deve fazer parte dos processos formativos é a atenção especial às necessidades das crianças, algo que é muito importante para a ação pedagógica desenvolvida junto aos bebês. As crianças muito pequenas necessitam interagir e receber atenção, sentindo-se acolhidas e protegidas. Não se trata de substituir os pais, mas dar a elas uma segurança afetiva, como salienta Falk (2016, p.26):

A segurança afetiva: estabelecimento e manutenção de relações interpessoais estáveis, contínuas, intimas e calorosas entre a criança e um número restrito de adultos bem conhecidos e uma relação afetiva privilegiada, autêntica, de um caráter específico, profissional, com uma pessoa (cuja forma e conteúdo são particulares dentro de âmbito institucional). O respeito e apoio indireto à sua atividade livre, espontânea, fruto da sua própria inciativa, assim como o respeito ao ritmo individual de seu desenvolvimento.

A proposição acima explicita que as crianças têm necessidades e a instituição que as recebe deve garantir que sejam satisfeitas. Identificamos assim, outro conteúdo que demanda ser discutido durante a formação coletiva.

Na relação entre professores, bebês e crianças muito pequenas, o desenvolvimento e as características $^{6}$ próprias dessa faixa etária são referências para o trabalho do professor junto aos pequeninos. Carvalho, Pedrosa e Rossetti-Ferreira (2012, p. 29) enunciam que:

Seres humanos nascem muito imaturos do ponto de vista motor e, portanto, extremamente dependentes do outro ser humano para a sua sobrevivência. É por intermédio do outro que a criança tem suas necessidades básicas atendidas, bem como acesso ao mundo, a seus significados e a formas de lidar com ele.

As considerações das autoras implicam que os professores devem ser preparados para incorporar esses conhecimentos em suas ações junto a pequena infância.

Outro saber importante para o processo de formação dos professores é o saber inerente às relações estabelecidas com as famílias. Essa relação deve estar pautada no respeito e na ética e

\footnotetext{
${ }^{6}$ Conforme as DCNEI, a organização dos tempos, espaços e materiais devem ser pensadas, dentre outros aspectos, a partir do reconhecimento das especificidades das faixas etárias, das singularidades individuais e coletivas das crianças, promovendo interações entre crianças da mesma idade e de idades diferentes.
} 
pressupõe a valorização da cultura e das comunidades de origem das crianças. De acordo com Garcia (2018, p. 30):

O envolvimento ativo das famílias nos processos de aprendizagem ocorre desde as impressões iniciais acerca do contexto institucional, assim como no desenvolvimento do processo educativo e por ocasião de compartilhar e celebrar as conquistas e os desafios.

Sem dúvida, a parceria com as famílias é um componente essencial em todos os momentos do trabalho da escola com as crianças pequenas e todo o esforço deve ser feito para que essas relações aconteçam de forma positiva e cooperativa.

Estamos diante de muitos saberes que precisam ser reconhecidos, aprendidos e incorporados às práticas dos professores da pequena infância. Podemos acrescentar ainda, as questões relacionadas à participação das crianças, permitindo que se expressem e comuniquem suas emoções e desejos, participando inclusive do planejamento das atividades. Goldschmied e Jackson (2006, p. 24) afirmam que:

Isso não representa apenas uma questão de convivência, mas, sim, do direito das crianças de serem respeitadas como indivíduos, de serem escutadas e levadas a sério, de forma que, ao ficarem mais velhas, elas possam tomar mais responsabilidades para si no sentido de exercer seus próprios direitos.

Numa perspectiva de atendimento, que respeite os direitos das crianças, promova o seu desenvolvimento integral e considere o caráter educativo deste atendimento, o trabalho do coordenador pedagógico como articulador do processo de formação dos professores é fundamental, oportunizando momentos de reflexão e aprendizado.

Em nossas observações e nos depoimentos coletados durante a pesquisa, foi possível perceber que a coordenadora tinha um olhar atento para esses saberes necessários ao professor. Contribuía com as discussões e reflexões sobre as práticas e ainda, estava atenta às atividades desenvolvidas pelas professoras e à organização dos espaços.

Algumas pesquisas, como as realizadas por Almeida e Placco (2009), André e Vieira (2010), Almeida (2010), Zumpano (2010) e Placco (2012) ao abordarem a atuação do coordenador pedagógico, nos remetem à importância das estratégias formativas que impulsionam a reflexão crítica entre os professores. Indicam em suas obras que, como articulador da formação, esse profissional deve fazer intervenções contínuas, sistemáticas e pertinentes junto aos professores, problematizando suas práticas. Com base nessas abordagens, trataremos adiante da relação entre o trabalho do coordenador pedagógico e a formação dos professores.

\section{O CEI E A FORMAÇÃO DE PROFESSORES: O PAPEL DA COORDENAÇÃO PEDAGÓGICA}

Partimos do pressuposto de que nenhuma prática pedagógica é neutra e as concepções de criança, de infância e educação infantil da equipe docente influenciam a forma como se dá o atendimento às crianças. Sendo assim, apostamos na formação dos profissionais que atuam nos CEIs para a superação de certas concepções e práticas que não contribuem para o desenvolvimento da autonomia das crianças e que também não possibilitam que elas ganhem voz e participação nesse processo educativo.

Observando atentamente uma unidade educativa de Educação Infantil, que atende crianças de 0 a 3 anos, durante a pesquisa, não foi difícil entender que a formação continuada, articulada pelo coordenador pedagógico, é um fator significativo para o desenvolvimento profissional dos professores. As atitudes da coordenadora revelavam compromisso com uma prática pedagógica efetiva junto as crianças pequenas, conforme está explícito no documento do MEC/SEB (SÃO PAULO, 2009, p. 58): 
Quando reivindicamos para a educação infantil a função de ser um lugar de educação e cuidado para as crianças, famílias e profissionais pensamos em alguns princípios orientadores que precisam ser transformados em práticas cotidianas, independente do campo de ação.

Diante deste enunciado e com base nas observações realizadas no interior do CEI, durante um semestre, consideramos que a coordenadora pedagógica, promoveu por meio de suas ações formativas os princípios explicitados acima. Nesse espaço, foi possível analisar criticamente como a sua atuação contribuiu para a garantia desses princípios de atendimento.

Como já foi explicitado, parte-se do pressuposto que a formação em serviço dos professores é um processo que deve ser articulado pelo coordenador pedagógico. No caso da rede municipal, há orientações legais específicas, demandando aos coordenadores pedagógicos um plano de trabalho que estabeleça metas, estratégias e cronogramas de formação continuada, o que evidencia a importância do envolvimento desses profissionais com o processo de formação continuada dos professores.

Partindo-se do que foi observado durante a pesquisa e dos dados obtidos, foi possível reafirmar a importância da formação continuada e compreender as relações entre a coordenadora pedagógica e as professoras ${ }^{7}$.

Ficou evidente que tanto a coordenadora pedagógica quanto a diretora do CEI compartilhavam a responsabilidade de articular e dar condições para que processo de formação da equipe acontecesse, para o que assumiam o papel de líderes, num movimento de busca para atingir cada vez mais a melhoria da qualidade do atendimento às crianças. Segundo Placco e Souza (2012, p. 51-52):

\begin{abstract}
[...] pode-se afirmar que um dos domínios necessários ao coordenador pedagógico que se pretenda mediador dos processos educacionais na escola diz respeito ao conhecimento do grupo de professores: os aspectos grupais e individuais, as histórias de cada um, seus valores e crenças, seus desejos e motivações, sua formação, sua experiência, os conhecimentos que domina, como desenvolve sua ação de ensinar, suas representações sobre escola, sobre ensino, sobre aluno, sobre aprendizagem, sobre as famílias etc.
\end{abstract}

As indicações das autoras serviram como balizas para analisar a atuação da coordenadora pedagógica no CEI e para compreender as articulações que ela estabelecia cotidianamente, entre os membros da equipe e a gestão, as estratégias formativas que utilizava nos espaços de discussão e os reflexos de sua atuação na prática pedagógica dos professores.

\title{
AS ESPECIFICIDADES DA COORDENAÇÃO PEDAGÓGICA NAS INSTITUIÇÕES QUE ATENDEM A PRIMEIRÍSSIMA INFÂNCIA.
}

A especificidade do trabalho da coordenação pedagógica em um CEI surge da própria especificidade do trabalho do professor junto a esta faixa etária. Essas especificidades são delimitadas por uma perspectiva que considera que o trabalho educativo com a pequena infância possui características singulares, que o distingue de outras etapas da educação básica. Cabe, portanto, à coordenação pedagógica de uma creche promover junto à equipe escolar e junto aos pais e comunidade, discussões acerca dessa singularidade.

Um dos primeiros aspectos que torna esse trabalho tão específico é o fato de que os CEIs atendem bebês que necessitam de todos os cuidados e, sobretudo, precisam ser reconhecidos como sujeitos históricos, com direito à proteção, à saúde, ao respeito, à brincadeira e à interação com outras crianças. Nem sempre essas peculiaridades são conhecidas ou reconhecidas pela equipe escolar, daí a

\footnotetext{
${ }^{7}$ Nesse caso, utilizamos a palavra professoras, pois no CEI em que ocorreu a pesquisa o corpo docente era formado exclusivamente por mulheres.
} 
importância de que a coordenação pedagógica esteja atenta a essas questões em seu plano de trabalho com os professores.

Outro aspecto que caracteriza essa especificidade é a imprescindível parceria entre a creche e as famílias, assim como o respeito às diferenças de papéis entre elas. As práticas pedagógicas devem atender às necessidades de cuidado das crianças, assim como garantir a elas o pleno direito à infância, à brincadeira e o acesso a experiências em diversos campos, dando-lhes voz e possibilitando sua autonomia e socialização.

$\mathrm{Na}$ interface entre o perfil dos professores da pequena infância e a formação continuada encontra-se um grande desafio para a coordenadora pedagógica. Ela precisa apropriar-se dos saberes a respeito da infância, mas também deve dominar os saberes relativos à formação de adultos professores e às estratégias de ação para promover as mudanças desejadas.

As atividades de formação devem ser organizadas e conduzidas de forma a promover, com os professores, a reflexão crítica sobre a prática, a articulação teoria e prática, o desenvolvimento de habilidades de pesquisa, planejamento e observação das práticas desenvolvidas.

A atuação do coordenador no CEI deve ser orientada para que as práticas desenvolvidas pelos professores junto às crianças sejam pautadas pelo respeito, orientação e os cuidados necessários. Os princípios legais e as teorias já apontadas devem ser os suportes para as ações e práticas que ocorrem no CEI. Bruno, Abreu e Monção (2012, p. 84) consideram que:

\begin{abstract}
Para desempenhar esse papel, cujo bojo está centrado no cultivo da pessoa integral e no qual as relações intra e interpessoais constituem tão forte apelo, o coordenador pedagógico precisa também cultivar em si mesmo o exercício permanente da busca de autoconhecimento e do desenvolvimento de sua percepção de si e do mundo. Necessita ainda assumir uma postura de formador que possa ser tomada como referência para o educador que atua diretamente com a criança, trazendo sempre à flor d'água a dimensão humana no trato com esses educadores, escutando-os, ajudando-os a pensar sobre sua prática e sobre si mesmos, favorecendo as iniciativas de trocas de experiências e acreditando em sua capacidade como educador.
\end{abstract}

As autoras enfatizam a necessidade de que o coordenador pedagógico desenvolva um movimento constante de autoconhecimento, para que possa assumir a postura de formador no trato com os professores, escutando-os, compreendendo-os, ajudando-os a refletir e favorecendo a troca de experiências, atuando, de forma a ser uma referência para eles.

Dessa perspectiva, a pesquisa realizada buscou entender como a coordenadora atuava e assumia seu papel de formadora das professoras. A problematização inicial respaldou-se no fato de quando os professores, em geral, não participam de processos formativos que lhes garanta a reflexão sobre as práticas, ficando a ação pedagógica comprometida pela falta de conhecimento e discussão dos princípios de um atendimento de qualidade.

A problematização inicial da pesquisa surgiu da experiência profissional da pesquisadora, dos estudos correlatos ao tema e das proposições de autores e de documentos oficiais que indicam que, apesar das dificuldades relacionadas à formação dos professores e às práticas desenvolvidas nas creches, relacionadas a velhos paradigmas, é exequível uma ação formativa que contribua para a superação dessas dificuldades.

Assim, o propósito principal da pesquisa foi analisar a atuação de uma coordenadora pedagógica muita respeitada e reconhecida pelos seus pares pelos saberes no trabalho de formação de professores e pela postura em defesa das crianças.

Durante a pesquisa foram coletados dados por meio de entrevistas com a coordenadora pedagógica e a diretora do CEI, observação dos horários coletivos de formação e eventos que estavam além do lócus de atuação da coordenadora, dentre eles: encontros formativos organizados pela diretoria regional de educação em que a coordenadora fez uma exposição a respeito do trabalho realizado em sua unidade. Foram realizadas ainda, discussões coletivas com as professoras do CEI em 
que atuava a coordenadora desde 2012 (grupo de discussão II) e com as professoras do CEI em que a coordenadora trabalhou entre 2004 a 2011 (grupo de discussão I). Além disso, alguns documentos da unidade foram examinados e posteriormente analisados, principalmente as avaliações das reuniões de formação. Foram utilizados durante a coleta de dados um diário de campo, um roteiro de observação e um roteiro de entrevista semiestruturada. Para as discussões coletivas com as professoras, foi utilizado um roteiro composto por questões que abordaram os seguintes aspectos: o significado dos horários coletivos em relação à formação continuada, a contribuição da coordenadora pedagógica e os aspectos distintivos da ação dessa coordenadora.

\section{O QUE FOI OBSERVADO EM RELAÇÃO A COORDENAÇÃO PEDAGÓGICA}

Os dados coletados foram organizados em relatos escritos, que foram submetidos a várias leituras para identificação dos temas mais significativos, tendo em vista os objetivos da pesquisa e o referencial teórico de apoio. Esse movimento de ir e vir entre os dados empíricos, os fundamentos e os propósitos da pesquisa resultaram em quatro categorias analíticas, que serão apresentadas e discutidas a seguir:

\section{a) A constituição profissional da coordenadora pedagógica}

De acordo com o que foi observado e por meio dos dados coletados, foi possível perceber que muitos fatores fizeram da coordenadora uma profissional que se destacava por sua atuação tão significativa diante das especificidades do trabalho com crianças de 0 a 3 anos.

Durante a coleta dos dados, a coordenadora pedagógica nos relatou seu percurso formativo, desde a formação inicial, passando pelos espaços de formação que frequentou, em busca de repertório para atuar na formação das professoras. Por meio desse relato, pudemos perceber que ela buscou novos conhecimentos, desde o início de sua carreira. Conforme adquiria novos conhecimentos, compartilhava-os com as professoras e as incentivava a pesquisar mais a respeito da cultura da infância.

Apresentamos abaixo um trecho da transcrição do relato da coordenadora que enfatiza os detalhes que nos ajudam a compreender os caminhos que a constituíram profissionalmente:

"Cursei o Magistério (Ensino Médio) e posteriormente, na PUC SP, o curso de Pedagogia. Busquei uma boa formação no Ensino Superior, uma vez que não tive no Magistério, uma formação que me oferecesse todos os elementos dos quais precisava. Depois, fiz pós-graduação na PUC, em Psicopedagogia. Comecei a buscar como professora, muita formação para além das formações promovidas pela SME. Fui aluna especial da USP e sempre fiz muitos cursos. Já como coordenadora, o grande diferencial na minha formação, foi a oportunidade de participar, no ano de 2000, do Programa de Formação Permanente para educadores Vivências Culturais, promovido pela SME. Foi então, que fiz meus primeiros contatos com a Casa Redonda9 e com o Instituto Brincante10. A partir daí, eu busquei formação nesses dois espaços. Fiquei um ano e meio fazendo a formação Educadores Brincantes no Instituto Brincante, o que foi importante para pensar a respeito da cultura da infância." (Coordenadora entrevistada).

Percebe-se pelo relato, que a coordenadora era movida pela busca de novos conhecimentos e pela ampliação de seu repertório cultural, desde o início de sua carreira. Esse interesse constante por cursos e atividades não só vinculadas ao desenvolvimento profissional, mas também ao crescimento pessoal revela o cuidado de si, como indicado por Bruno, Abreu e Monção (2012). 


\title{
b) As estratégias formativas no trabalho da coordenadora
}

Entre as características profissionais da coordenadora, destacou-se a capacidade de dividir seus saberes a respeito da pequena infância. Apresentou-se como uma educadora atenta às necessidades das professoras, sem deixar de considerar o cuidado e a educação das crianças pequenas na creche.

Ficou evidente por meio dos depoimentos colhidos, que ela tinha objetivos definidos em relação à formação continuada das professoras. Preparava-se constantemente para esse desafio. Duas professoras do grupo I, no momento da discussão coletiva declararam:

\begin{abstract}
“A coordenadora é minha mestra, em quem me inspiro até hoje. Ela começou de uma forma muito delicada e poética. Começou a resgatar a nossa infância. Resgatar a criança que fomos um dia, para termos algo a oferecer às nossas crianças. Ela tentava fazer com que resgatássemos os sentimentos que tínhamos quando fazíamos as descobertas e as brincadeiras. Fomos conhecendo autores maravilhosos, nos apaixonamos por Manoel de Barros. Ela foi resgatando a importância de uma infância feliz. Percebemos que a criança precisa ser compreendida. Aprendi com ela que o professor não anda à frente da criança, mas atrás. Nós começamos a filmar o que estávamos trabalhando com a criança e depois analisávamos essas filmagens."
\end{abstract}

"Ela trazia uma teoria por traz das vivências, fazíamos a relação com a nossa prática. Ela nos fazia acreditar, mesmo com algumas críticas. Aquele trabalho contagiava a gente de tal forma que mergulhávamos, tentando saber e conhecer cada vez mais."

Os depoimentos tocam em pontos essenciais: a forma de abordar as professoras, a ressignificação dos conteúdos da formação e a oportunidade de colocar em prática os conceitos discutidos. Percebeu-se também, a importância do processo de formação vivenciado pelas professoras por meio da ação dessa coordenadora. Suas particularidades profissionais influenciaram e inspiraram as professoras que revelaram no decorrer das entrevistas, ter muito respeito por essa profissional.

O apoio da diretora do CEI foi fundamental em relação ao trabalho de formação e às ações propostas. Ambas compartilhavam as mesmas concepções em relação ao trabalho pedagógico com as crianças e possuíam grande conhecimento a respeito da infância:

Ela sempre foi parceira neste processo de formação. Acho que tanto eu como ela, plantamos algumas sementes. Ela tem uma visão a respeito desta relação com a natureza. Acredito que um currículo para os bebês passa por esse caminho. (Diretora).

A relação entre ambas era muito respeitosa, pois compartilhavam dos mesmos desejos para aquele espaço. Consideramos ser esse um fator muito importante para a construção de um projeto educativo.

\section{c) O conteúdo das formações}

Os diversos espaços que frequentou (cursos e vivencias) foram dando o tom à sua atuação como coordenadora pedagógica. Conforme adquiria novos conhecimentos, tentava compartilhá-los com as professoras e as incentivava a pesquisar mais a respeito da cultura da infância. O depoimento abaixo revela como valorizava a arte na formação cultural do professor:

Outra formação que tem sido muito importante é a Ciranda de Filmes. Um projeto que nasceu com a Fernanda Heinz, quando ela produziu o filme As sementes do nosso quintal. Juntamente com a cineasta Patrícia, elas organizaram esse ciclo de exibição de filmes. Eu organizei também, uma exibição no CEU Meninos, do filme e chamei os professores para a exibição e a discussão, pois as imagens do filme são muito inspiradoras. (Coordenadora).

Encontram-se ainda, nos depoimentos, declarações que explicitam a valorização do contato da criança com a natureza e com o meio ambiente: 
Tenho feito uma parceria com o Instituto Alana. Vou ao Alana buscar materiais e organizei recentemente, um encontro a respeito da importância do contato da criança com a natureza. Fizemos uma parceria e pude disponibilizar alguns materiais para as escolas convidadas. Os materiais do Território do Brincar, da Fernanda, têm sido muito inspiradores. Tenho discutido com as professoras a respeito da importância de as crianças construírem o próprio brinquedo. (Coordenadora).

Percebe-se, pelos relatos, a iniciativa da coordenadora ao buscar atividades e materiais que enriquecessem o repertório dos docentes. Os depoimentos evidenciam ainda, a articulação entre as atividades vivenciadas por ela nos espaços de formação e os processos formativos que organizava junto às professoras. Na discussão coletiva com as professoras colhemos o seguinte depoimento:

\begin{abstract}
Entendemos que a criança precisa de um tempo para fazer as descobertas e se encantar e somente depois, você traz mais conhecimentos para que ela se aprofunde. São tantas coisas que aprendemos que a gente até se perde na hora de colocar. Quando comparamos quando entramos na rede. Eu tinha ensino médio. Eles te colocavam numa sala e você tinha que se virar. Era isso que tinha que ser feito. Quando chegou a coordenadora e fez um trabalho brilhante, como ela fez... Foi um processo demorado porque a gente tem que estudar muito, fazer muita pesquisa. Eu aprendi a buscar fora da escola. Eu estava sempre em um teatro infantil, em cursos diferenciados, porque queria me alimentar mais. Quando ela colocava algum conhecimento, aquilo encantava tanto, que nós saiamos para fora buscando sempre mais e mais, para poder dar o melhor para as crianças! (Professora do grupo I).
\end{abstract}

Este depoimento revela o cuidado com a coordenação dos horários de formação e as estratégias formativas que utilizou nesse processo. Para mobilizar as professoras, ela utilizou recursos formativos como: contação de histórias, experiências com arte e cantigas populares, assim como o contato com a natureza. Dessa forma, as professoras entenderam a importância de determinadas vivencias para as crianças. A coordenadora pedagógica demonstrou ter uma visão clara a respeito de seu papel e de sua responsabilidade frente ao processo de formação continuada das professoras.

\title{
d) Como é avaliada pela equipe
}

Os relatos das professoras e da diretora da creche revelaram a importância que a formação continuada desenvolvida por ela, teve para o desdobramento do trabalho pedagógico nessa unidade educativa. A sua busca por espaços que lhe oferecessem o contato com novos conhecimentos, influenciaram a maneira como ela conduziu a formação junto às professoras. Seu interesse e disposição para aprender coisas novas e sua capacidade de encantar-se foram fatores decisivos para conduzir seu percurso e constitui-la como uma coordenadora comprometida com o desenvolvimento profissional das professoras.

Semestralmente, de acordo com a legislação que regulamenta a elaboração do Projeto Especial de Ação (PEA), que é a proposta de formação para os horários coletivos que ocorrem no CEI, é realizada pelos integrantes do projeto, pela equipe gestora e pelo conselho de escola, uma avaliação dessa proposta em relação à pertinência do tema elencado e dos avanços que esse espaço de formação tem proporcionado. Tivemos acesso a essa avaliação semestral, realizada pelos participantes e por cada professora. Ao ler as avaliações, foi possível compreender como as professoras participantes deste projeto avaliaram as ações formativas da coordenadora pedagógica.

De acordo com as avaliações lidas, as professoras consideraram que foram oferecidos referenciais teóricos consistentes e coerentes com a proposta pedagógica do CEI. Esses referenciais despertaram no grupo o interesse por aprofundar os conhecimentos a respeito dos bebês e crianças. As professoras avaliaram que a coordenadora estava comprometida com a formação e que havia um clima de respeito e valorização, que foi fortalecido pelas Quintas Autorais, espaço possibilitado às professoras para compartilhar as ações pedagógicas mais importantes para elas. Foram orientadas para 
registrar as práticas, contextualizá-las e apresentá-las no coletivo. Essa apresentação foi feita por meio de texto, vídeo ou imagem.

Todas as professoras apontaram, em suas avaliações, que os estudos trouxeram oportunidades de aprender e mudar a prática. Contudo, apontaram que deveria haver mais tempo para estudar a respeito da questão dos tempos e espaço na creche, assim como para planejar, pensar e discutir esses aspectos. As professoras valorizaram as contribuições e as mediações que a coordenadora realizava por meio de materiais, apoio e orientação para o trabalho..

\section{PARA CONCLUIR}

Neste artigo, foram abordados alguns dados da pesquisa realizada no trabalho final do mestrado, colocando-se o foco na formação continuada e no papel da coordenadora pedagógica que atua na creche.

Consideramos que, uma educação de qualidade é o que as instituições públicas de educação devem ter como meta. No entanto, essa meta está relacionada a fatores administrativos, sociais, políticos, dentre outras ações que fortaleçam o trabalho pedagógico da equipe escolar.

As discussões apresentadas neste texto convergiram para os seguintes aspectos:

- As práticas pedagógicas do professor de bebês e de crianças muito pequenas possuem especificidades e dimensões complexas;

- Os saberes de que necessitam os professores da pequena infância, em grande parte, são determinados pelas características singulares da faixa etária que atendem;

- A trajetória profissional e pessoal, assim como as experiencias formativas de que compartilham são constituintes da profissionalidade dos professores.

- A formação continuada nos contextos de atuação do professor contribui para o desenvolvimento profissional dos docentes

- A reflexão crítica não se estabelece nos espaços educativos por si mesma, mas pelo investimento em ações intencionalmente dirigidas, cuidadosamente planejadas e conduzidas.

Nesse contexto, a coordenação pedagógica, tem um papel primordial, promovendo discussões e reflexões acerca dessas especificidades, e garantindo aos professores um espaço de formação continuada em que as práticas pedagógicas possam ser pensadas, repensadas e cuidadas. Cabe à coordenação pedagógica mediar, por meio de diferentes recursos, a reflexão dos professores.

Após a observação do trabalho da coordenadora pedagógica e das relações que foram estabelecidas com as professoras, famílias, crianças, assim como dos dados coletados nas entrevistas e discussão coletiva com as professoras, foi possível entender com mais cuidado o papel desse profissional.

Um dos aspectos que fez parte das observações realizadas durante a pesquisa refere-se às urgências que perpassam a rotina do coordenador pedagógico e a compreensão superficial de alguns sujeitos sobre o seu papel, fato comum em muitas escolas/CEIs. É comum que o coordenador pedagógico tenha um sentimento de solidão frente às demandas que lhe são impostas. No entanto, percebeu-se no caso estudado, que o apoio da direção do CEI foi fundamental para a construção de muitas práticas pedagógicas e para o planejamento de muitas ações junto às crianças e aos professores.

No decorrer da pesquisa percebeu-se que o fato da coordenadora pedagógica conhecer, pesquisar e construir conhecimentos a respeito da pequeníssima infância e suas especificidades constituiu o seu diferencial positivo e facilitou aos professores o (re)conhecimento do contexto em que trabalhavam, assim como a aquisição de subsídios teóricos para rever suas práticas. 
A importância do processo de formação vivenciado pelas educadoras e as particularidades das estratégias formativas dessa coordenadora fizeram com que seu trabalho fosse reconhecido e respeitado, o que contagiava as professoras. Seu entusiasmo, dedicação e forma delicada, generosa e sutil de intervenção foram destacados em diversos depoimentos.

Na discussão coletiva, algumas professoras reconheceram que o trabalho da coordenadora era fundamental para a descoberta de novas formas de atuação junto às crianças. A importância da experiência e do conhecimento da coordenadora, em relação à infância, seu encantamento pela poesia, pela arte, pela cultura popular e pela que natureza sustentavam os projetos realizados na unidade.

Diante dos dados coletados durante a pesquisa e da literatura que versa acerca do papel do coordenador pedagógico, destacamos que esse profissional deve oferecer apoio e incentivo aos professores, observar as ações pedagógicas, fazer apontamentos necessários a respeito das práticas observadas e promover atividades variadas para o desenvolvimento profissional dos docentes.

Nossas conclusões robustecem a necessidade de que o coordenador pedagógico tenha possibilidade e oportunidade de se desenvolver profissionalmente, de forma que se tornem conscientes do seu papel articulador na formação continuada, assumindo as responsabilidades por esse processo. $\mathrm{O}$ coordenador necessita de formação continuada e apoio para compreender sua própria prática e adquirir os saberes necessários à sua atuação.

\section{REFERENCIAS}

ALMEIDA, L. R.; PLACCO, V. M. N. de S. O papel do coordenador pedagógico. Revista Educação, São Paulo, ano 12, n. 142, fev. 2009.

ALMEIDA, L. R. O coordenador pedagógico ante o desafio de articular e mobilizar a equipe escolar para tecer o projeto pedagógico. In.: GUIMARÃES, A. A. et al. O coordenador pedagógico e a educação continuada. São Paulo: Loyola, 2010. p. 25-36.

ANDRÉ, M. E. D. A. Estudo de caso em pesquisa e avaliação educacional. Brasília: Líber Livro, 2008.

ANDRÉ, M. E. D. A.; VIEIRA, M. M. da S. O coordenador pedagógico e a questão dos saberes. In.: ALMEIDA, L.R.; PLACCO, V. M. N. S. O coordenador pedagógico e questões da contemporaneidade. São Paulo: Loyola, 2010. p. 11-24.

BARBOSA, M. C. S. As especificidades da ação pedagógica com os bebês. SEMINÁRIO NACIONAL: CURRÍCULO EM MOVIMENTO - PERSPECTIVAS ATUAIS, 1,. 2010, Belo Horizonte. Anais eletrônicos... Belo Horizonte: MEC, 2010. Disponível em: http://portal.mec.gov.br/docman/dezembro-2010-pdf/7154-2-2-artigo-mec-acao-pedagogica-bebes-mcarmem/file. Acesso em: 14 abr. 2019.

BARRETO, E. S. S. Cursos precisam preparar para a docência. Difusão de Ideias, São Paulo, p.2-5, nov. 2011. Entrevista concedida à Ana Paula Novaes.

BRASIL. Ministério da Educação. Conselho Nacional de Educação. Câmara de Educação Básica. Resolução $\mathbf{n}^{0}$ 5, de 17 de dezembro de 2009. Fixa as Diretrizes Curriculares Nacionais para a Educação Infantil. Brasília: MEC, 2009.

BRASIL. Ministério da Educação. Conselho Nacional de Educação. Câmara de Educação Básica. Parecer $n^{0}$ 20, de 11 de novembro de 2009. Revisão das Diretrizes Curriculares Nacionais para a Educação Infantil. Brasília: MEC, 2009. 
BRASIL. Ministério da Educação. Conselho Nacional de Educação. Câmara de Educação Básica. Resolução no 1, de 07 de abril de 1999. Institui as Diretrizes Curriculares Nacionais para a Educação Infantil. Brasília: MEC, 1999.

BRUNO, E. B. G; ABREU L. C.; MONÇÃO, M. A. G. Os saberes necessários ao coordenador pedagógico de educação infantil: reflexões, desafios e perspectivas. In.: PLACCO, V. M. N. S.; ALMEIDA, L. (orgs.). $\mathbf{O}$ coordenador pedagógico e o atendimento à diversidade. São Paulo: Loyola, 2012. p. 77-98.

CAMPOS, M. M. Profissionais de educação infantil: desafios para a política educacional. In.: SEVERINO, A. J.; FAZENDA, I. C. (orgs.). Políticas educacionais: o ensino nacional em questão. Campinas: Papirus, 2003. p. 151-161.

CAMPOS, M. M. A formação de professores para crianças de 0 a 10 anos: modelos em debate. Educação \& Sociedade, São Paulo, v. 20, n. 68, p. 126-142, dez. 1999.

CAMPOS, M. M.; FULLGRAF, J.; WIGGERS, V. A qualidade da educação infantil brasileira: alguns resultados de pesquisa. Cadernos de Pesquisa, São Paulo, v. 36, n. 127, p. 87-128, jan./abr. 2006.

CARvalho, A. M. A.; PEDrosA, M. I.; ROSSETI-FERREIRA, M. C. Aprendendo com a criança de zero a seis anos. São Paulo: Cortez, 2012.

DAGNONI, A. P. R. Quais as fontes dos saberes das professoras de bebês? 2011. $184 \mathrm{f}$. Dissertação (Mestrado em Educação) - Programa de Mestrado Acadêmico em Educação, Universidade do Vale do Itajaí, Itajaí, 2011. Disponível em: http://siaibib01.univali.br/pdf/Ana\%20Paula\%20Rudolf\%20Dagnoni.pdf. Acesso em: 14 abr. 2019.

FALK, J. A estabilidade por meio da continuidade e qualidade dos cuidados e das relações. In.: FALK, J. (org.). Abordagem Pikler: educação infantil. São Paulo: Omnisciencia, 2016. p. 25-39.

FRANCO, D. S. Gestão de creches para além da assistência social: transição e percurso na Prefeitura de São Paulo de 2001 a 2004. 2009. 159 f., Dissertação (Mestrado em Educação) Faculdade de Educação, Universidade de São Paulo, São Paulo, 2009.

GATTI, B. A. Formação de professores no Brasil: características e problemas. Educação \& Sociedade, São Paulo, v. 31, n. 113, p. 1355-1379, out./dez. 2010. Disponível em: https://www.scribd.com/doc/166345871/Gatti-Formacao-de-Professores-No-Brasil.Acesso em: 17 abr. 2019.

GARCIA, A. C. Bebês e suas professoras no berçário: estudo de interações à luz de pedagogias participativas. 2018. 152 f., Dissertação (Mestrado em Educação) - Faculdade de Educação, Universidade de São Paulo, São Paulo, 2018.

GOLDSCHMIED, E.; JACKSON, S. Educação de 0 a 3 anos: atendimento em creche. Porto Alegre: Artmed, 2006.

HORN, M. G. S. Sabores, cores, sons, aromas: a organização dos espaços na Educação Infantil. Porto Alegre: Artmed, 2004.

IMBERNÓN, F. Formação continuada de professores. Porto Alegre: Artmed. 2010

IMBERNÓN, F. Formação docente e profissional: formar-se para a mudança e a incerteza. São Paulo: Cortez, 2011.

LÜDKE, M.; ANDRÉ, M. E. D. A. Pesquisa em educação: abordagens qualitativas. Rio de Janeiro: EPU, 2014. 
PLACCO, V. M. N. S; SOUZA, V. L. T. Diferentes aprendizagens do coordenador pedagógico. In.: PLACCO, V. M. N. S.; ALMEIDA, L. (orgs.). O coordenador pedagógico e o atendimento à diversidade. São Paulo: Loyola, 2012. p. 47-61.

SÃO PAULO. Secretaria Municipal de Educação. Revista Magistério. Edição especial, n. 3. 15 anos Centro de Educação Infantil. São Paulo: SME/COPED, 2017.

SÃO PAULO. Secretaria Municipal de Educação. Orientação Normativa n ${ }^{0} 1$, de 11 de setembro de 2015. Estabelece os Padrões Básicos de Qualidade na Educação Infantil Paulistana. São Paulo: SME/DOT, 2015.

SÃO PAULO. Secretaria Municipal de Educação. Decreto $n^{\circ}$ 54.453, de 10 de outubro de 2013. Fixa as atribuições dos Profissionais de Educação que integram as equipes escolares das unidades educacionais da Rede Municipal de Ensino. Diário Oficial Cidade de São Paulo, São Paulo, 11 out. 2013. p. 3.

SÃO PAULO. Secretaria do Governo Municipal. Lei n 13574, de 12 de maio de 2003. Dispõe sobre a transformação e inclusão no quadro do magistério municipal, do quadro dos profissionais de educação dos cargos de auxiliar de desenvolvimento infantil, pedagogo e diretor de equipamento social, e dá outras providências. Diário Oficial Cidade de São Paulo, São Paulo, 13 maio 2003.

ZUMPANO, V. A. A. O coordenador pedagógico e o seu papel na formação continuada em serviço do professor de educação infantil (creche). 2010. 194 f. Dissertação (Mestrado em Educação) - Programa de Estudos Pós-Graduados da Psicologia da Educação, Pontifícia Universidade Católica de São Paulo. São Paulo, 2010. Disponível em: http://www.sapientia.pucsp.br/tde_busca/arquivo.php?codArquivo=12282. Acesso em: 22 maio 2015. 